\section{What this paper suggests}

Women taking high doses of folate throughout pregnancy may be more likely to die from breast cancer in later life than women taking no folate

\section{What research is needed now}

This may be a chance finding, so further studies should examine the association between folate supplementation in pregnancy and risk of breast cancer rats fed diets with sufficient folate, ${ }^{5}$ whereas rats fed a high dose folate diet had similar levels of tumorigenesis to deficient rats. ${ }^{5}$ Our data are preliminary and these findings require confirmation.

Contributors: DC did the fieldwork and the analysis. AN wrote the first draft. All the authors commented on this and subsequent drafts. AN is guarantor.

Funding: The original study had a project grant from the board of management for the Aberdeen Special Hospitals. Glaxo supplied the tablets. A project grant from the British Heart Foundation supported the reanalysis and follow up.

Competing interests: None declared.

Ethical approval: Multi-Centre Research Ethics Committee and the local Grampian Research Ethics Committee.

the risk of deaths attributable to breast cancer was twice as great. This increased risk in deaths attributable to breast cancer is unlikely to be due to competing causes as the number of deaths was small and all cause mortality appeared to be greater. The increase in mortality and in death from breast cancer with high doses of folate could be a chance finding. The number of deaths was small, the confidence intervals were wide, and we had no prespecified hypothesis that taking folate supplements in pregnancy would increase the risk of cancer. As this randomised trial was of high quality, bias and confounding are unlikely explanations for our findings. A recent study indicated that rats fed diets deficient in folate had increased mammary tumorigenesis compared with
1 MRC Vitamin Study Research Group. Prevention of neural tube defects: results of the Medical Research Council vitamin study. Lancel results of the $1991 ; 338: 131-7$.

2 Lucock M. Is folic acid the ultimate functional food component for disease prevention? BMJ 2004;328:211-4.

3 Hall MH. Folic acid deficiency and congenital malformation. J Obstet Gynaecol Br Commonw 1972;79:159-61.

4 Charles DHM, Ness AR, Campbell D, Davey Smith G, Whitley E, Hall $\mathrm{MH}$. Folate and birth outcome: reanalysis of a large randomised controlled trial. Paediatr Perinat Epidemiol 2005;19. (In press.)

5 Kotsopolous J, Kyoung-Jin S, Martin R, Choi M, Renlund R, McKerlie C, et al. Dietary folate deficiency suppresses $N$ - methyl- $N$-nitrosoureainduced mammary tumorigenesis in rats. Carcingenesis 2003;24:937-44.

(Accepted 7 October 2004)

\title{
Commentary: Folic acid fortification remains an urgent health priority
}

Godfrey P Oakley, Jack S Mandel

Department of Epidemiology, Rollins School of Rublic Health of Emory University, 1518 Clifton Road, Atlanta, GA 3032 Godfrey P Oakley research professor Jack S Mandel Rollins professor and chair

Correspondence to: G P Oakley gpoakley@ mindspring.com
Charles and colleagues report a non-statistically significant association between short term prenatal consumption of folic acid and breast cancer. ${ }^{1}$ As the authors note, even though these data are from a randomised controlled trial, they had no prespecified hypothesis. The randomised controlled trial sought to evaluate the effect of antenatal folate consumption and pregnancy outcomes, not breast cancer. Only 31 breast cancer deaths were found, and the confidence intervals were wide and include one. We believe that the most likely explanation for the reported association is chance.

In contrast to the results reported by Charles and colleagues, the existing literature indicates that increased chronic consumption of folate and higher blood folate concentrations lower the risk of breast cancer, especially among women who consume one or more drinks of alcohol a day. Shrubsole and colleagues found, in a population based study of 1321 cases and 1382 controls, that dietary folate is inversely associated with breast cancer (odds ratio $0.71 ; 95 \%$ confidence interval 0.56 to 0.92 ). ${ }^{2}$ In a prospective follow up cohort, Zhang and colleagues did a nested case-control study, which included 712 breast cancer cases and 712 controls. Comparing women in the upper quintile for blood folate with those in the lowest quintile, they reported a protective relative risk of 0.73 (95\% confidence interval 0.50 to 1.07). Among women consuming more than $15 \mathrm{~g}$ of alcohol a day, they found a highly protective relative risk of 0.11 ( 0.02 to 0.59$){ }^{3}$

Mutagenic mechanisms by which folate deficiency might induce cancer have also been sought. The current search is focused on DNA that is damaged by imbalanced base excision repair of DNA that had uracil incorporated because there was not enough folate to provide sufficient thymine. ${ }^{4}$ Fenech and colleagues have looked at in vitro human cell systems and found an inverse dose-response effect between mutagenic end points and concentrations of folic acid in the culture. ${ }^{5}$ Thus, there are biologically plausible mechanisms by which increasing folic acid consumption would lower the risk for breast cancer.

Our argument that Charles' and colleagues' finding is a chance one is buttressed by these epidemiological and mutation studies, which indicate that more folic acid is likely to prevent breast cancer rather than to cause it. Charles' report should not deter mandatory folic acid fortification of wheat and corn flour around the world. Mandatory fortification should be immediately implemented for the known benefits of preventing birth defects and anemia. Folic acid fortification in the United States was followed each year with a reduction in deaths from strokes and heart attacks that is greater than the annual deaths from vehicular crashes, indicating another important public health improvement from fortification. Inertia on mandatory folic acid fortification continues to be bad policy.

Competing interests: GPO is coinventor (while at CDC, compensation will be under the regulations of $\mathrm{CDC}$ ) of a patent that covers adding folic acid to contraceptive pills and JSM is a paid consultant to Ortho McNeil on this issue.

1 Charles D, Ness AR, Campbell D, Smith GD, Hall MH. Taking folate in pregnancy and risk of maternal breast cancer BMJ 2004;329:1375-6.

Shrubsole MJ, Jin F, Dai Q, Shu XO, Potter JD, Hebert JR, et al. Dietary folate intake and breast cancer risk: results from the Shanghai Breast Cancer Study. Cancer Res 2001;61:7136-41.

3 Zhang SM, Willett WC, Selhub J, Hunter DJ, Giovannucci EL, Holmes $\mathrm{MD}$, et al. Plasma folate, vitamin B6, vitamin B12, homocysteine, and risk of breast cancer. J Natl Cancer Inst 2003;95:373-80.

4 Cabelof C, Raffoul J, Nakamura J, Kapoor D, Abdalla H, Heydari A. Imbalanced base excision repair in response to folate deficiency is accelerated by polymerase beta haploinsufficiency. J Biol Chem 2004;279:36504-13.

5 Wang X, Fenech M. A comparison of folic acid and 5-methyltetrahydrofolate for prevention of DNA damage and cell death in human lymphocytes in vitro. Mutagenesis 2003;18:81-6. 